\title{
Fenologia de cultivares de soja em diferentes datas de semeadura em terras baixas
}

\author{
Eduardo Cerezer Stochero \\ Instituto Federal de Educação, Ciência e Tecnologia Farroupilha (IFFar) \\ (eduardocerezer@hotmail.com) \\ Ivan Carlos Maldaner \\ Instituto Federal de Educação, Ciência e Tecnologia Farroupilha (IFFar) \\ (ivan.maldaner@iffarroupilha.edu.br) \\ Camila Bisognin Meneghetti \\ Instituto Federal de Educação, Ciência e Tecnologia Farroupilha (IFFar) \\ (meneghetti402@gmail.com) \\ Cristhian Matias Halberstadt \\ Instituto Federal de Educação, Ciência e Tecnologia Farroupilha (IFFar) \\ (cristianmatias01@gmail.com) \\ Felipe Tascheto Bolzan \\ Instituto Federal de Educação, Ciência e Tecnologia Farroupilha (IFFar) \\ (felipebolzan93@hotmail.com) \\ Eduardo Anibele Streck \\ Instituto Federal de Educação, Ciência e Tecnologia Farroupilha (IFFar) \\ (eduardo.streck@iffarroupilha.edu.br)
}

\begin{abstract}
Resumo: O presente trabalho teve por objetivo analisar o comportamento fenológico de cultivares de soja em diferentes épocas de semeadura em terras baixas, determinando a altura das plantas, duração do ciclo e dos subperíodos de desenvolvimento. O experimento foi realizado na área experimental do Instituto Federal Farroupilha - Campus São Vicente do Sul, sendo composto por seis cultivares de soja. $\mathrm{O}$ delineamento experimental ocorreu em blocos ao acaso, com quatro repetições. Foram realizadas três épocas de semeadura (19/10, 29/11 e 29/12/2018). A parcela foi composta por seis linhas com 5 metros de comprimento e espaçamento de $0,45 \mathrm{~m}$ entre fileiras, na densidade de 30 plantas $/ \mathrm{m}^{2}$. Para o acompanhamento fenológico foram demarcadas duas plantas por parcela, e avaliadas duas vezes por semana seu estágio fenológico. A altura das plantas foi determinada após as plantas atingirem a maturação fisiológica. Realizou-se a análise de variância para verificar se havia diferença entre as variáveis analisadas, sendo aplicado o teste de Tukey $(P<0,05)$ para comparação de médias. $A$ análise de variância mostrou que houve interação dos fatores época de semeadura e cultivar para todas as variáveis. Portanto, diferentes épocas de semeaduras influenciam na altura das plantas, duração do ciclo e dos subperíodos de desenvolvimento da cultura.
\end{abstract}

Palavras Chaves: Desenvolvimento da soja; Épocas de semeadura; Áreas de várzeas.

\section{Phenology of soy cultivars in different sowing dates on low lands}

Abstract: The present work aimed to analyze the phenological behavior of soybean cultivars in different sowing dates in lowlands, determining plant height, cycle duration and development subperiods. The experiment was carried out in the experimental area of the Federal Institute Farroupilha - São Vicente do Sul Campus, and consisted of six soybean cultivars. The experimental design was randomized blocks with four replications. Three sowing dates were performed (10/19, 11/29 and 12/29/2018). The plot consisted of six rows with 5 meters in length and spacing of $0.45 \mathrm{~m}$ between rows, at a density of 30 plants $/ \mathrm{m}$. For the phenological monitoring, two plants were demarcated per plot, and their phenological stage was evaluated twice a week. Plant height was determined after the plants reached physiological maturity. The analysis of variance was performed to verify if there was a difference between the analyzed variables, applying the Tukey test $(\mathrm{P}<0.05)$ for comparison of means. The analysis of variance showed that there was interaction of the factors sowing time and cultivar for all variables. Therefore, different sowing times influence plant height, cycle duration and crop development subperiods.

Keywords: Soy development; Sowing Dates; Lowland areas. 


\section{INTRODUÇÃO}

O cultivo da soja no Brasil está aumentando com o passar dos anos, tanto em área cultivada quanto em produtividade. Em especial no Rio Grande do Sul, o qual nos últimos anos houve um acréscimo de aproximadamente 750 mil hectares entre a safra 2013/14 para a safra $2017 / 18$, alcançando um total de 17,15 milhões de toneladas de grãos, superior aos 12,86 milhões de toneladas obtidos na safra 2013/14 (CONAB, 2018).

Esse aumento nas áreas de soja que vem ocorrendo no estado, é decorrente da ocupação dos solos arrozeiros com o cultivo da soja, onde essas áreas ocupam cerca de 5,4 milhões de hectares e representam cerca de $20 \%$ da área total do Estado, resultando em uma expansão significativa nas áreas com o cultivo da soja (GOMES, et al., 2006).

De acordo com o levantamento realizado pelo Instituto Rio Grandense do Arroz (IRGA), a área de soja em ambiente de várzea no Rio Grande do Sul, passou de 56.000 hectares na safra 2010/11 para mais de 290.000 hectares na safra de 2017/18. Juntamente com a produtividade, que passou de $2.204 \mathrm{~kg}$ por ha na safra 2010/11 para $2.656 \mathrm{~kg}$ por ha na safra 2017/18 (IRGA, 2018).

Essa evolução no cultivo de soja em áreas orizícolas está ocorrendo em grande parte devido à grande ascensão da cultura nos últimos anos e, ao fácil acesso à venda no comércio internacional (PAZZIN, 2012). Conforme Marchesan (2016), nos últimos anos os elevados preços da soja, e a desvalorização do preço do arroz irrigado, incentivou os produtores a produzir soja em substituição as culturas que vinham sendo trabalhadas. Com isso, a perspectiva é de que o produtor aumente as áreas com o cultivo da soja. Além disso, o uso da soja é uma boa alternativa para a rotação de culturas em áreas de cultivo do arroz irrigado, pois, facilita o controle de plantas invasoras, em especial o arroz vermelho, pela aplicação de herbicidas com diferentes mecanismos de ação, e intervém no ciclo de pragas e doenças (VIZZOTTO, 2014).

No entanto, existem algumas limitações nessas áreas, a deficiente drenagem natural da água associado ao relevo plano, acaba gerando acúmulo de água na superfície após períodos chuvosos. Em anos de ocorrência do fenômeno El Niño, a precipitação pluviométrica tende a ser acima do normal no estado do Rio Grande do Sul, o que resulta em certos anos o excesso de água no solo. O excesso hídrico é desfavorável para a cultura da soja, pois causam modificações na atmosfera do solo, 
como, a deficiência de oxigênio, acúmulo de gás carbônico, metano, etileno, gás sulfídrico, e a redução da respiração aeróbica. Essa modificação da atmosfera prejudica o crescimento das raízes, o que afeta diretamente na produtividade da cultura (COSTA, 1996). Onde, dentro da mesma espécie algumas plantas podem se adaptar, se tornando tolerantes ao encharcamento (BAILEY-SERRES \& VOESENEK, 2008).

Outro impasse é a variação na época de semeadura da soja que tem efeito em diferentes proporções no desenvolvimento das plantas entre cultivares existentes no mercado. Nesse sentido, o fator época possui influência sobre várias características importantes da soja, tais como a duração do ciclo, alterações na duração dos subperíodos de desenvolvimento, altura de planta, especialmente nos genótipos muito sensíveis à temperatura e fotoperíodo, visto que, a soja é uma espécie muito sensível ao comprimento do dia, o qual regula a indução floral e o crescimento das plantas (OLIVEIRA, 2010).

O porte reduzido pode resultar em perdas na produtividade e acaba dificultando a colheita, de outro modo, o crescimento excessivo pode ocasionar o acamamento das plantas, dificultando a colheita, resultando na queda da produtividade (OLIVEIRA, 2010). O fator época também pode causar uma maturação fisiológica desigual das plantas e expor a cultura a fatores climáticos desfavoráveis ao desenvolvimento da cultura.

Dessa forma, através do monitoramento da fenologia das plantas, que se refere ao estudo das diferentes fases de desenvolvimento da planta, nos possibilita entender a relação entre as características morfológicas e fisiológicas das plantas e os fatores do ambiente, em especial os de origem meteorológica (VENTURA et al., 2009). Os elementos meteorológicos de maior relevância a serem considerados, no caso da cultura da soja são fotoperíodo e temperatura do ar (EMBRAPA, 2008). Assim como, os elementos meteorológicos sofrem oscilação no decorrer do ano, com a mudança das épocas de semeadura é possível modificar a fenologia da cultura da soja (KOMORI et al., 2004).

Além disso, os solos de várzea podem ocasionar situações desfavoráveis a cultura da soja, onde a principal questão relacionada a uma boa produtividade de uma cultivar, é sua adaptação á ambientes propícios à períodos de alagamento e baixos teores de oxigênio, possibilitando bons retornos econômicos ao produtor (PINTO et al., 2013). 
Desta forma, o conhecimento da duração das fases e do ciclo de desenvolvimento de acordo com a época de semeadura, poderá facilitar na assistência técnica e auxiliar os produtores de soja nas práticas corretas de manejo de pragas e doenças, que exigem para seu sucesso, aplicações em estádios de desenvolvimento bem definidos, podendo assim alcançar o máximo potencial genético de cada cultivar.

O objetivo do presente trabalho foi analisar o comportamento fonométrico e fenológico de cultivares de soja em diferentes épocas de semeadura em terras baixas, se tornando uma importante informação sobre o cultivo de soja em terras baixas, para produtores e a assistência técnica, auxiliando no planejamento e manejo da cultura da soja.

\section{MATERIAIS E MÉTODOS}

O presente trabalho foi conduzido na safra 2018/19, na área experimental do Instituto Federal Farroupilha, Campus São Vicente do Sul, localizada na Depressão Central do Estado do Rio Grande do Sul (Latitude: 29 41' 30' S Longitude: 54 40' 46" W, Altitude: 129 m). A área utilizada é denominada terras baixas ou várzea, com tipo de solo classificado como Planossolo Háplico Eutrófico arênico (STRECK et al., 2008), onde, no último ano era manejado com a cultura do arroz irrigado.

Nessa safra de 2018/19 verificou-se a ocorrência do fenômeno El Niño, que é caracterizado pelo excesso de precipitações pluviométricas na região Sul do Brasil, especialmente no Rio Grande do Sul. Pensando nisso, foram realizados canais de drenagens para facilitar o escoamento da água superficial e possibilitar as condições de trabalho, posteriormente foi efetuado o preparo da área para a semeadura, com a realização de duas gradagens e abertura de novos canais para escoar o excesso de água das chuvas.

As seis cultivares de soja avaliadas possuem diferentes grupos de maturação (GM), todas com hábito de crescimento indeterminado Brasmax Raio IPRO, (GM = 5,0); Brasmax Elite IPRO, (GM = 5,5); Brasmax Delta IPRO, (GM = 5,9); Brasmax Garra IPRO, (GM=6,3); BS IRGA 1642 IPRO, (GM=6,4); e Brasmax Ícone IPRO, $(\mathrm{GM}=6,8)$. Essas cultivares foram selecionadas pela sua melhor adaptação ao cultivo de terras baixas. A adubação de base, inoculação das sementes com o inoculante Gelfix (Bactérias Bradyrhizobium elkanii SEMIA 587 e SEMIA 5019), o tratamento das sementes com fungicida e inseticida, e o controle de pragas e doenças foram 
realizados de acordo com as recomendações técnicas para a cultura. Durante o desenvolvimento das plantas, foram realizadas duas aplicações de herbicidas, com o uso do glifosato, nas dosagens indicadas pela bula do produto.

O delineamento experimental foi de blocos ao acaso, em esquema de parcelas subdivididas, com quatro repetições. foram realizadas três épocas de semeadura (19/10, 29/11 e 29/12/2018). Cada repetição foi constituída de seis parcelas, sendo uma de cada cultivar. A parcela era composta por seis linhas com 5 metros de comprimento e espaçamento de 0,45 m entre fileiras, na densidade de 30 plantas $/ \mathrm{m}^{2}$ e profundidade de semeadura de $0,03 \mathrm{~m}$. A semeadura foi realizada de modo manual, com abertura dos sulcos e as sementes dispostas manualmente, para a emergência das parcelas foi considerada quando $50 \%$ do total de plantas de cada fileira estavam com os cotilédones acima do solo.

Em relação ao acompanhamento fenológico da cultura foram demarcadas com arame colorido duas plantas representativas em cada parcela, onde foram avaliadas duas vezes por semana seu estágio de desenvolvimento. A colheita foi realizada conforme as cultivares dos respectivos grupos de maturação de cada época de semeadura atingiam sua maturação fisiológica, denominada pelo estágio R8. A colheita foi realizada de forma manual, sendo que, para a sua avaliação dos componentes de rendimento foram colhidas as plantas nas três linhas centrais da parcela, no comprimento de 1 metro cada linha.

Para a determinação da soma térmica, os dados de temperaturas mínima e máxima diárias do ar e também de precipitações e umidade relativa durante o período experimental foram coletadas na estação meteorológica convencional, pertencentes ao Instituto Nacional de Meteorologia (INMET), dados na (TABELA 1), localizada no Instituto Federal Farroupilha - Campus São Vicente do Sul. A temperatura média (Tmed) diária do ar foi obtida pela média aritmética das temperaturas mínima e máxima diária do ar. A soma térmica diária (STd, ํㅡ dia) foi calculada mediante o método (GILMORE \& ROGERS, 1958; ARNOLD, 1960):

Método: $\mathrm{STd}=(\mathrm{Tmed}-\mathrm{Tb}) .1$ dia quando $\mathrm{Tb}<\mathrm{Tmed} \leq \mathrm{Tot} \mathrm{e}$

$$
\text { STd }=(\text { Tot }-\mathrm{Tb}) .(\text { Tmax }- \text { Tmed }) /(T \text { max }- \text { Tot }) \text { quando Tot }<\text { Tmed } \leq \text { Tmax }
$$

onde: Tb é a temperatura base, Tot é a temperatura ótima e Tmax é a temperatura máxima para o desenvolvimento da soja. Utilizou-se $\mathrm{Tb}=7,6 \stackrel{\circ}{\circ} \mathrm{C}$, Tot $=31^{\circ} \mathrm{C}$ e $\operatorname{Tmax}=40^{\circ} \mathrm{C}$ para o cálculo da soma termina da fase vegetativa (VE-R1), e Tb $=0,0$ 
${ }^{\circ} \mathrm{C}$, Topt $=21,5{ }^{\circ} \mathrm{C}$ e $\operatorname{Tmax}=38,7{ }^{\circ} \mathrm{C}$ para o cálculo da soma térmica da fase reprodutiva (R1-R8) (SETIYONO et al., 2007). A soma térmica diária foi acumulada a partir da emergência, resultando na soma térmica acumulada (STa), onde foi calculada por STa $=\Sigma$ STd.

Tabela 1 - Temperatura média, precipitação pluvial e umidade relativa do ar por decêndio, em São Vicente do Sul, de outubro a maio do ano agrícola 2018/2019.

\begin{tabular}{|c|c|c|c|c|}
\hline \multirow[b]{2}{*}{ Meses } & & Temperatura $\left({ }^{\circ} \mathrm{C}\right)$ & \multirow{2}{*}{$\begin{array}{c}\text { Umidade Relativa (\%) } \\
\text { Média }\end{array}$} & \multirow{2}{*}{$\begin{array}{c}\text { Precipitação }(\mathrm{mm}) \\
\text { Total }\end{array}$} \\
\hline & & Média & & \\
\hline \multirow[t]{2}{*}{ Out. } & 3 & 20,31 & 70,98 & 25,2 \\
\hline & 1 & 22,46 & 68,84 & 6,6 \\
\hline \multirow[t]{3}{*}{ Nov. } & 2 & 22,51 & 66,86 & 140,2 \\
\hline & 3 & 23,11 & 70,27 & 88 \\
\hline & 1 & 20,78 & 55,64 & 0 \\
\hline \multirow[t]{3}{*}{ Dez. } & 2 & 24,64 & 77,94 & 217,4 \\
\hline & 3 & 25,40 & 75,31 & 54,2 \\
\hline & 1 & 24,37 & 82,31 & 0 \\
\hline \multirow[t]{3}{*}{ Jan. } & 2 & 23,64 & 84,35 & 165,2 \\
\hline & 3 & 27,23 & 74,12 & 13 \\
\hline & 1 & 24,61 & 71,37 & 4,6 \\
\hline \multirow[t]{3}{*}{ Fev. } & 2 & 23,17 & 76,13 & 131,8 \\
\hline & 3 & 23,33 & 70,24 & 23 \\
\hline & 1 & 23,22 & 73,83 & 51,2 \\
\hline \multirow[t]{3}{*}{ Mar. } & 2 & 21,95 & 80,19 & 131,8 \\
\hline & 3 & 20,20 & 73,54 & 0 \\
\hline & 1 & 21,75 & 78,75 & 83,8 \\
\hline \multirow[t]{2}{*}{ Abr. } & 2 & 20,58 & 80,29 & 26,6 \\
\hline & 3 & 19,67 & 85,96 & 130,4 \\
\hline
\end{tabular}

*1, 2 e 3 representam os decêndios do mês.

Fonte: Elaborado pelos autores.

As variáveis estudadas foram as durações em ${ }^{\circ} \mathrm{C}$ dia, dos períodos compreendidos entre os estádios fenológicos VE e R1, R1 e R5, VE e R8, e R1 e R8. Os estágios VE, R1, R5 e R8 correspondem, à emergência, início do florescimento, início do enchimento de grãos e ponto de colheita, respectivamente, determinados através da escala de FEHR \& CAVINESS (1977). E, após as plantas atingirem seu estágio R8, foi determinado à variável altura de planta, onde, foram avaliadas 5 plantas de cada parcela e realizado a média dos resultados, assim, estabelecendo a altura média de cada parcela.

As análises estatísticas foram realizadas com auxílio do software livre Sisvar, sendo executado a análise de variância para verificar se ocorreu diferença entre as variáveis analisadas de cada cultivar, e se existe interação com as épocas de semeadura, sendo aplicado o teste de Tukey $(P<0,05)$ para comparação de médias. 
Na interação significativa, a análise foi desdobrada dentro de cada fator.

\section{RESULTADOS E DISCUSSÕES}

A análise de variância mostrou que houve interação dos fatores época de semeadura e cultivar para todas as variáveis, duração do ciclo a partir da emergência até a maturação fisiológica (VE-R8), duração do período vegetativo (VE-R1), duração do período do início do florescimento até início do enchimento de grãos (R1-R5), duração do período reprodutivo (R1-R8) e altura de plantas.

Nesse caso a precisão experimental pode ser considerada como alta, visto que, os coeficientes de variação para todas as variáveis analisadas foram inferiores ou próximos a 10\% (GOMES, 1990).

Para a duração total de ciclo VE-R8 das cultivares analisadas, todas sofreram variações estatísticas entre as três épocas de semeadura, e dentro de cada época. De maneira geral, a duração em ${ }^{\circ} \mathrm{C}$ dias do período VE-R8 de todas as cultivares avaliadas foram diminuindo a partir da primeira época de semeadura, em relação a segunda e terceira época (Figura 1), exceto a cultivar BMX RAIO IPRO que apresentou o maior valor acumulado em ${ }^{\circ} \mathrm{C}$ dias do período VE-R8 na segunda época de semeadura. Tais resultados estão em concordância com os obtidos por vários autores, entre eles Peixoto et al. (2010) e Trentin et al. (2013).

Em decorrências das cultivares pertencerem a GM diferentes, de maneira geral foi possível observar que nas três épocas de semeadura, ocorreu uma redução da duração total do ciclo dentro de cada época conforme a redução do GM das cultivares, com algumas exceções devido à proximidade dos GM das cultivares. Esses resultados estão de acordo com os obtidos pelos autores (JUNIOR ZANON et al., 2015), que da mesma forma, verificou que em uma mesma região, quanto menor o GM, menor a duração do ciclo.

Vale ressaltar a importância do planejamento da lavoura, a fim de evitar o acúmulo de atividades em um curto período, em especial as aplicações de agrotóxicos e colheita. Por isso, a importância em trabalhar com cultivares de diferentes GM, em diferentes épocas de semeadura. Dessa maneira, em áreas com possibilidade de alagamento do solo é essencial o planejamento levando em conta as alterações no 
ciclo de cada cultivar, de maneira a evitar problemas com o manejo da cultura e diminuindo as perdas, principalmente na colheita.

Figura 1 - Duração em ${ }^{\circ} \mathrm{C}$ dia, da duração do ciclo que vai da emergência até a maturação fisiológica (VE-R8), de 6 cultivares de soja, em três épocas de semeadura (19/10, 29/11 e 29/12/2018), no ano agrícola de 2018-2019 em São Vicente do Sul, RS. (Médias seguidas pela mesma letra, comparadas para cada cultivar, não diferem entre si pelo teste de Tukey, a $\mathrm{P}<0,05$ de probabilidade).

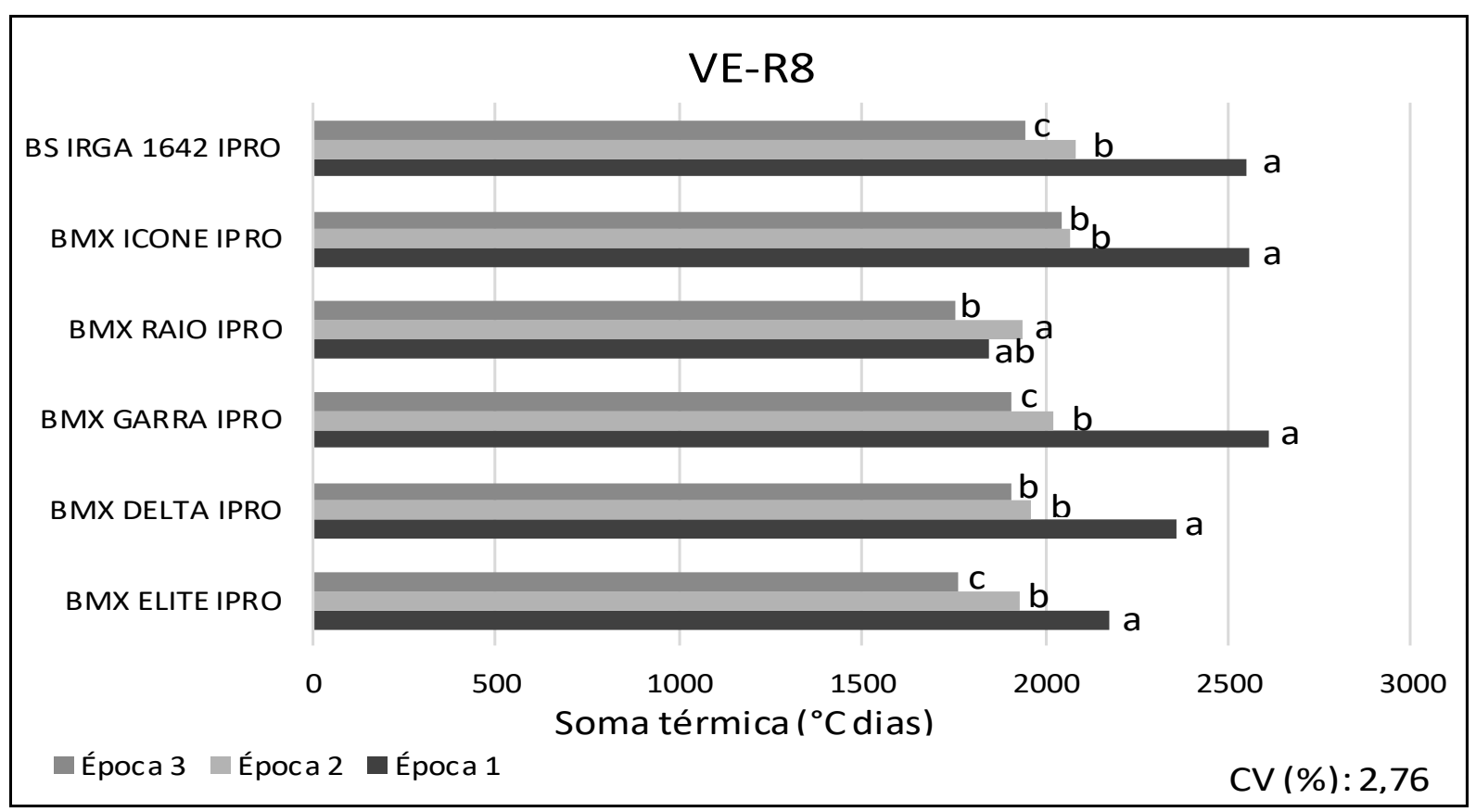

Fonte: Elaborado pelos autores.

Em relação ao estágio vegetativo VE-R1, para efeito de época em cada cultivar, todas as cultivares manifestaram diferença estatística entre as épocas de semeadura, exceto a cultivar BMX RAIO IPRO. Dentro de cada época, houve diferenças significativas entre as cultivares testadas nas três épocas de semeadura (Figura 2). E conseguimos notar, que todas as cultivares tiveram maior duração desse período de desenvolvimento na segunda época de semeadura, com a exceção da cultivar BMX RAIO IPRO que não houve diferença estatística entre as três épocas analisadas. Os resultados obtidos são semelhantes com os encontrados por Oliveira (2010), que com dadas de semeadura da época 1 e 2 próximas a do presente trabalho, no qual também obteve uma maior duração do período VE-R1 na segunda data de semeadura.

A explicação da menor duração desse período vegetativo na primeira época pode estar relacionada com maior exposição a dias curtos em relação a segunda época. Há informações de diversos autores, entre eles Rodrigues et al. (2001), que estão em concordância com tal fato. Eles também alegam a importância de dias curtos no estímulo da antese e na redução do período vegetativo. Já a segunda época que teve a maior duração desse período, as plantas foram expostas a dias mais longos no 
início do ciclo, o que resultou num prolongamento do período vegetativo. Conforme (RODRIGUES et al., 2001), dias longos acarretam o desenvolvimento dos órgãos reprodutivos de forma mais lenta.

Como também, as condições de excesso de precipitações presenciadas durante o período vegetativo das plantas, na primeira época (Tabela 1), podem ter influenciado na celeridade do florescimento, através do estresse causado pelo excesso hídrico. Apesar da segunda época ter tido a maior duração dessa fase VE-R1 entre as épocas avaliadas, esse período poderia ter manifestado uma maior duração, mas em ocorrência do excesso de chuva e encharcamento do solo presenciado na fase vegetativa da segunda época, pode ter influenciado na indução da fase reprodutiva das cultivares.

Pelos mesmos motivos que a primeira época, a terceira época da mesma forma apresentou redução na fase vegetativa, por estar exposta por um período maior de dias curtos, tais dados estão de acordo com os dados obtidos pelo autor Junior Zanon et al. (2015).

Os resultados obtidos pela cultivar BMX RAIO IPRO evidenciam que a mesma apresenta um período juvenil mais curto que as outras cultivares avaliadas, por ser a primeira a florescer sob condições de dias curtos, que é um aspecto desfavorável do ponto de vista prático, pela redução do porte e dificuldades na colheita.

Esses resultados estão de acordo com as características existentes em cada material, pelo motivo de que em praticamente todas as épocas, as cultivares que pertencem aos grupos de maturação mais tardio apresentaram maiores duração desse período de juvenilidade em relação as cultivares de ciclo precoce. A cultivar BMX RAIO IPRO apresentou a menor duração desse período vegetativo nas três épocas, pelo motivo de pertencer a um grupo de maturação de maior precocidade, entre as cultivares analisadas. 
Figura 2 - Duração em ${ }^{\circ} \mathrm{C}$ dia, da duração do período vegetativo (VE-R1), de 6 cultivares de soja, em três épocas de semeadura (19/10, 29/11 e 29/12/2018), no ano agrícola de 2018-2019 em São Vicente do Sul, RS. (Médias seguidas pela mesma letra, comparadas para cada cultivar, não diferem entre si pelo teste de Tukey, $\mathrm{P}<0,05$ de probabilidade).

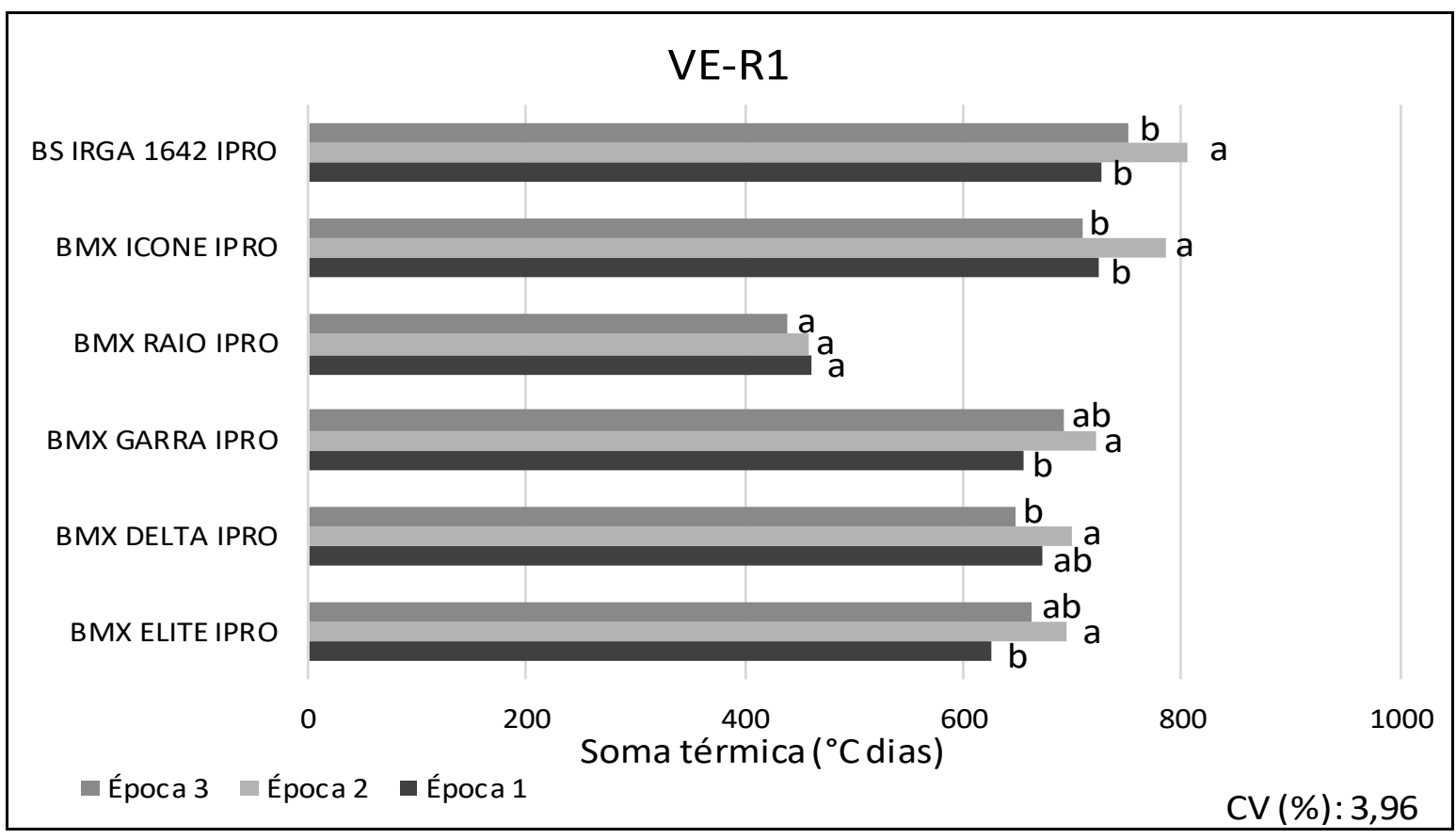

Fonte: Elaborado pelos autores.

Para a variável duração em ${ }^{\circ} \mathrm{C}$ dias no período compreendido como início do florescimento até início do enchimento de grãos (R1-R5), para o efeito de época em cada cultivar, todas as cultivares manifestaram diferença estatística entre as épocas de semeadura. A efeito de cultivar dentro de cada época, houve diferenças significativas entre as cultivares testadas nas três épocas de semeadura. Se observou nitidamente a maior duração desse período na primeira época de semeadura, exceto para a cultivar BMX RAIO IPRO que teve efeito contrário, apresentando entre as três épocas a menor duração na primeira época (Figura 3). Os seguintes resultados estão de acordo com os verificados pelos autores Rodrigues et al. (2008) e Trentin et al. (2013), onde também observaram uma tendência de redução desse período com o tardar da época de semeadura. 
Figura 3. Duração em ${ }^{\circ} \mathrm{C}$ dia, da duração início do florescimento até início do enchimento de grãos (R1R5), de 6 cultivares de soja, em três épocas de semeadura (19/10, 29/11 e 29/12/2018), no ano agrícola de 2018-2019 em São Vicente do Sul, RS. (Médias seguidas pela mesma letra, comparadas dentro de cada cultivar, não diferem entre si pelo teste de Tukey, $\mathrm{P}<0,05$ de probabilidade).

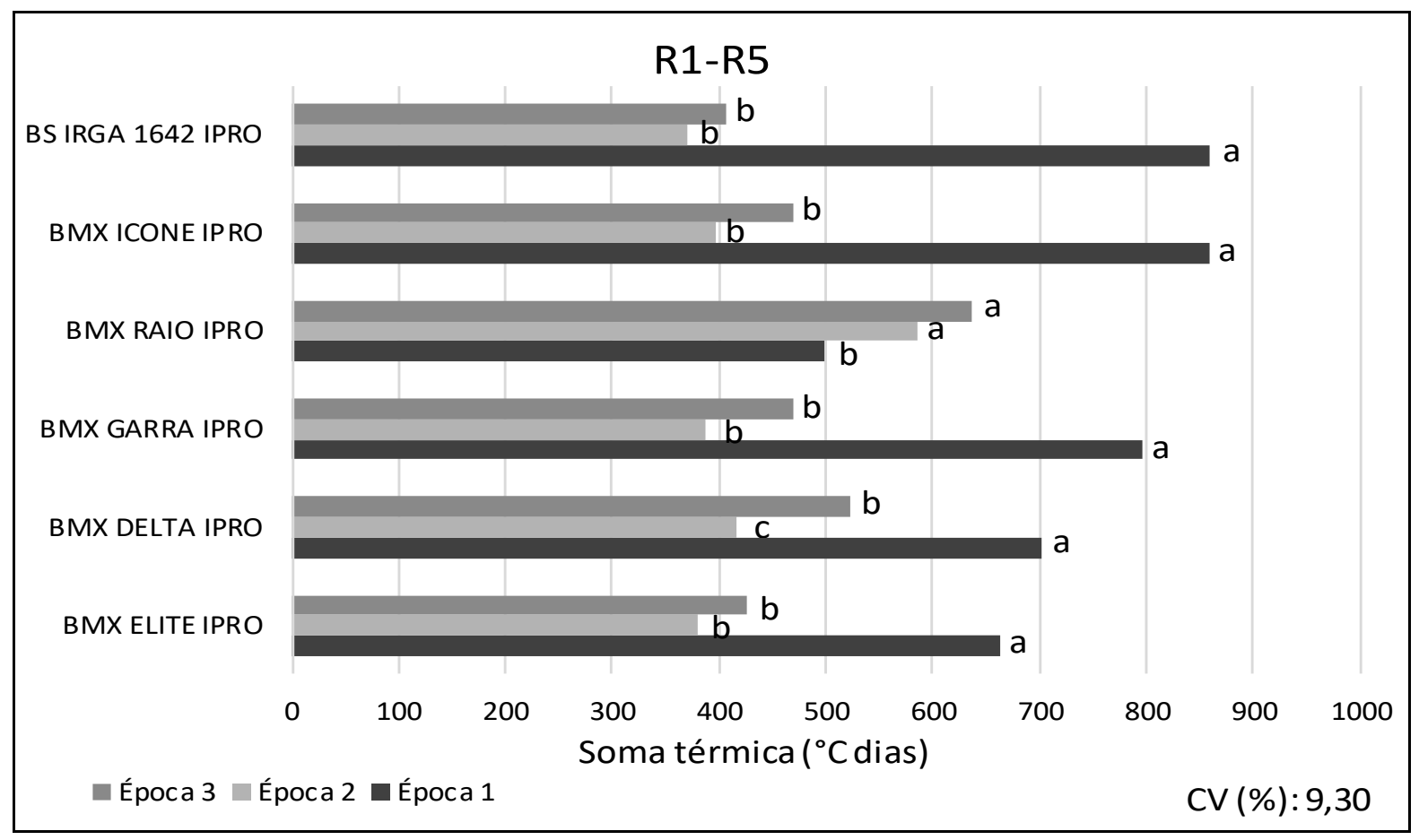

Fonte: Elaborado pelos autores.

Para a fase reprodutiva (R1-R8) para o desdobramento de época em cada cultivar, todas as cultivares avaliadas sofreram variações significativas entre as três épocas de semeadura. E para o efeito de cultivar em cada época, nas três épocas ocorrem diferenças estatísticas entre as cultivares. Onde se observou que para todas as cultivares, a não ser a cultivar BMX RAIO IPRO, que a maior duração foi expressa na primeira época de semeadura (Figura 4).

Nesse caso, todas cultivares avaliadas apresentaram uma redução expressiva na duração desse período na segunda época de semeadura em relação a primeira época, menos a cultivar BMX RAIO IPRO. Tais resultados são compatíveis aos encontrados por Oliveira, (2010). A partir da segunda época se semeadura, apesar de significativa de algumas cultivares, a redução desse período foi de menor escala. Vários autores mencionam o encurtamento do período reprodutivo em semeaduras mais tardias, entre eles Peixoto et al. (2000) e Junior Zanon et al. (2015).

A explicação para a ocorrência dessa situação, se deve ao fato que na segunda e terceira época, a partir do florescimento as condições de temperatura, precipitação e 
fotoperíodo foram mais favoráveis para o desenvolvimento da soja, causando aceleramento dessa fase.

Figura 4. Duração em ${ }^{\circ} \mathrm{C}$ dia, do período reprodutivo (R1-R8), de 6 cultivares de soja, em três épocas de semeadura (19/10, 29/11 e 29/12/2018), no ano agrícola de 2018-2019 em São Vicente do Sul, RS.

(Médias seguidas pela mesma letra, comparadas para cada cultivar, não diferem entre si pelo teste de Tukey, $\mathrm{P}<0,05$ de probabilidade).

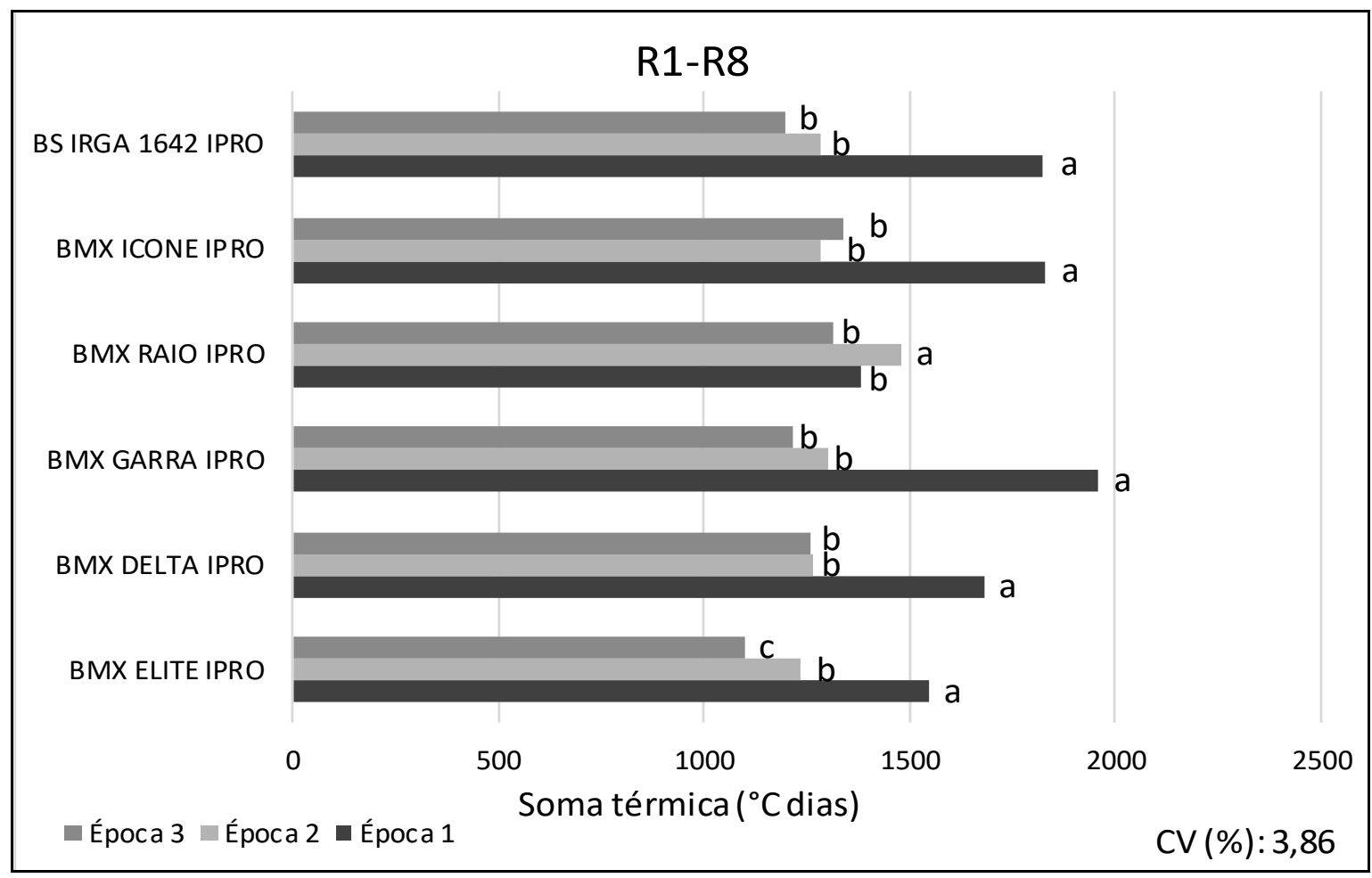

Fonte: Elaborado pelos autores.

Para a variável altura de plantas, para o efeito de cultivar em cada uma das épocas, houve uma tendência de maior altura de plantas nas épocas 1 e 2 , exceto para a cultivar BMX RAIO IPRO.

Dentro de cada época, houve diferença significativa entre as cultivares testadas apenas na época 1, onde a cultivar BMX GARRA IPRO apresentou a maior estatura com $87,6 \mathrm{~cm}$, mas não diferiu da cultivar BMX ICONE IPRO que teve uma estatura de $79,6 \mathrm{~cm}$, e com o menor porte apresentado, a cultivar BMX RAIO IPRO com 42,9 cm, dados expressos na (Tabela 2). Nas cultivares avaliadas, as maiores alturas observadas são de cultivares que pertencem a GM mais tardio, onde tiveram uma maior duração do período vegetativo. 
Fenologia de cultivares de soja em diferentes datas de semeadura em terras baixas

Tabela 2 - Estatura de planta, em centímetros, dos 6 genótipos avaliados em três épocas de semeadura (19/10, 29/11 e 29/12/2018), no ano agrícola de 2018/2019 em São Vicente do Sul, RS.

\begin{tabular}{ccccc}
\hline \multirow{2}{*}{ Cultivar } & \multicolumn{3}{c}{ Época } & \multirow{2}{*}{ Média } \\
\cline { 2 - 4 } & 1 & 2 & 3 & \\
\hline BMX ELITE IPRO & $72,7 \mathrm{Ab}$ & $69,0 \mathrm{Aa}$ & $47,5 \mathrm{Ba}$ & $63,01 \mathrm{~b}$ \\
BMX DELTA IPRO & $72,0 \mathrm{Ab}$ & $68,1 \mathrm{Aa}$ & $51,8 \mathrm{Ba}$ & $63,95 \mathrm{~b}$ \\
BMX GARRA IPRO & $87,6 \mathrm{Aa}$ & $76,4 \mathrm{Aa}$ & $60,9 \mathrm{Ba}$ & $74,93 \mathrm{a}$ \\
BMX RAIO IPRO & $42,9 \mathrm{Bc}$ & $64,1 \mathrm{Aa}$ & $47,5 \mathrm{Ba}$ & $51,46 \mathrm{c}$ \\
BMX ICONE IPRO & $79,6 \mathrm{Aab}$ & $70,9 \mathrm{Aa}$ & $57,1 \mathrm{Ba}$ & $69,18 \mathrm{ab}$ \\
BS IRGA 1642 IPRO & $68,9 \mathrm{Ab}$ & $67,3 \mathrm{Aa}$ & $54,5 \mathrm{Ba}$ & $63,53 \mathrm{~b}$ \\
\hline Média & $70,59 \mathrm{~A}$ & $69,25 \mathrm{~A}$ & $53,19 \mathrm{~B}$ & \\
& & & & CV (\%): 10,96 \\
\hline
\end{tabular}

*Médias seguidas pela mesma letra maiúscula na linha e minúscula na coluna, não diferem entre si pelo teste de Tukey, $\mathrm{P}<0,05$ de probabilidade.

Fonte: Elaborado pelos autores.

Em semeaduras tardias acabam ocasionando o florescimento precoce, redução do ciclo e consequentemente a estatura de planta (Tabela 2). Sendo assim, quanto menor a exposição das plantas a dias com fotoperíodos longos, mais precoce será seu florescimento ainda quando a planta se encontra em um porte baixo, o que pode influenciar na perda de produtividade. Os resultados mencionados nesse trabalho estão de acordo com os encontrados pelos autores Meotti et al. (2012), que também evidenciou menor estaturas de plantas em semeaduras tardias.

\section{CONCLUSÃO}

Os resultados obtidos através desse trabalho é uma importante informação, visto que o cultivo de soja em terras baixas está aumentando nos últimos anos (IRGA, 2018), e a tendência é que continue aumentando em rotação com o arroz irrigado. Esses dados proporcionam aos produtores e a assistência técnica, um fácil entendimento da duração de ciclo, subperíodos de desenvolvimento e altura das cultivares de soja providas de diferentes grupos de maturação, dispostas em três épocas de semeadura, podendo assim, auxiliar no planejamento da lavoura e manejo da cultura.

A época de semeadura expressou influência sobre a duração do período entre a emergência da planta até a floração e maturação. 
Com o tardar da data de semeadura, ocorre uma redução do período reprodutivo, e também do ciclo total de desenvolvimento (com exceção da cultivar BMX RAIO IPRO), independente do grupo de maturação.

As semeaduras de outubro e final de dezembro resultam na redução da fase vegetativa na maioria das cultivares quando comparadas a semeadura na segunda quinzena de novembro.

As cultivares que se mostraram mais adaptadas para as condições de terras baixas em semeaduras dentro da época preferencial (15 Out/15 Nov), foram a BMX GARRA IPRO, BMX ICONE IPRO e BS IRGA 1642 IPRO, todas pertencem a ciclo médio, e apresentam as maiores durações do período vegetativo e reprodutivo, resultando em uma estatura mais adequada, e também maior tempo de recuperação para um eventual déficit hídrico na fase reprodutiva, em especial no enchimento de grãos.

Em semeaduras antecipadas utilizar cultivares de ciclo médio ou tardio, pois cultivares de ciclo precoce nessas condições estão sujeitas a uma redução do porte pelo florescimento antecipado.

Nas semeaduras tardias as plantas apresentam um porte baixo, dificultando a colheita mecanizada, originando em perdas na produção. As semeaduras na segunda quinzena de outubro e na segunda quinzena de novembro resultam em maiores alturas de plantas.

\section{REFERÊNCIAS}

ARNOLD, CHARLES Y. Maximum-minimum temperatures as a basis for computing heat units. In: Proceedings. American Society for Horticultural Science. 1960. p. 682-92.

BAILEY-SERRES, J.; VOESENEK, L. A. C. J. Flooding stress: acclimations and genetic diversity. Annu. Rev. Plant Biol., v. 59, p. 313-339, 2008. Referencial de internet disponível em:

<https://www.annualreviews.org/doi/abs/10.1146/annurev.arplant.59.032607.092752>. Acesso em: 13, jan, 2019;

Companhia Nacional de Abastecimento - CONAB. Acompanhamento de safra brasileira: safra 2017/2018, grãos, décimo segundo levantamento, p. 108-116, Brasília, DF, set, 2018. Referencial de internet disponível em: <www.conab.gov.br>. Acesso em: 13, jan, 2019; 
COSTA, J. A. Cultura da soja. Ed. de Ivo Manica e José Antonio Costa, 1996. 233 p. Acesso em: 13, jan, 2019;

EMBRAPA, SOJA. Tecnologias de produção de soja - Região central do Brasil 2009 e 2010. Londrina: Embrapa Soja: Embrapa Cerrados: Embrapa Agropecuária Oeste, Londrina, PR, 2008. 262 p. Referencial de internet disponível em:

$<$ https://www.infoteca.cnptia.embrapa.br/infoteca/bitstream/doc/242861/1/Tecnol2009.p df>. Acesso em: 14, jan, 2019;

FEHR, WALTER R.; CAVINESS, CHARLES E. Stages of soybean development. 1977. Referencial de internet disponível em: <

https://lib.dr.iastate.edu/specialreports/87/>. Acesso em: 23, abr, 2019;

GILMORE, E. C.; ROGERS, J. S. Heat units as a method of measuring maturity in corn 1. Agronomy Journal, v. 50, n. 10, p. 611-615, 1958. Referencial de internet disponível em:

<https://dl.sciencesocieties.org/publications/aj/abstracts/50/10/AJ0500100611>. Acesso em: 23, abr, 2019;

GOMES, A. D. S., da SILVA, C. A. S., PARFIT, J. M. B., PAULETTO, E. A., \& PINTO, L. F. S. .Caracterização de indicadores da qualidade do solo, com ênfase às áreas de várzea do Rio Grande do Sul. Embrapa Clima Temperado-Documentos (INFOTECAE), 2006. Referencial de internet disponível em: < https://www.infoteca.cnptia.embrapa.br/bitstream/doc/746124/1/documento169.pdf>. Acesso em: 14, jan, 2019;

GOMES, F. P. (1990). Curso de estatística experimental (13 ed.). Piracicaba: Nobel. $468 \mathrm{p}$;

Instituto Nacional de Meteorologia (INMET). Estação automática de São Vicente do Sul. Referencial de internet disponível em: <http//www.inmet.gov.br>. Acesso em: 17, mar, 2019;

Instituto Rio Grandense do Arroz - IRGA. Soja em rotação com arroz - Evolução área e produtividade. 2018. Referencial de internet disponível em: <https://irga.rs.gov.br>. Acesso em: 12, jan, 2019;

JUNIOR ZANON, A., WINCK, J. E. M., STRECK, N. A., ROCHA, T. S. M. D., CERA, J. C., RICHTER, G. L., ... \& MARCHESAN, E. Desenvolvimento de cultivares de soja em função do grupo de maturação e tipo de crescimento em terras altas e terras baixas. Bragantia, 74, n. 4, 2015. Referencial de internet disponível em: <http://www.scielo.br/pdf/brag/2015nahead/0006-8705-brag-1678-44990043.pdf>. Acesso em: 17, jan, 2019;

KOMORI, E., HAMAWAKI, O. T., DE SOUZA, M. P., SHIGIHARA, D., \& BATISTA, A. M.. Influência da época de semeadura e população de plantas sobre características agronômicas na cultura da soja. Bioscience Journal, v. 20, n. 3, 2004. Referencial de internet disponível em:

<http://www.seer.ufu.br/index.php/biosciencejournal/article/download/6536/4270>. Acesso em: 17, jan, 2019; 
MARCHESAN, ENIO. Desenvolvimento de tecnologias para cultivo de soja em terras baixas. Revista Eletrônica Competências Digitais para Agricultura Familiar, v. 2, n. 1, p. 4-19, 2016. Referencial de internet disponível em: <http://owl.tupa.unesp.br/recodaf/index.php/recodaf/article/view/22>. Acesso em: 13, jan, 2019;

MEOTTI, G. V., BENIN, G., SILVA, R. R., BECHE, E., \& MUNARO, L. B. Épocas de semeadura e desempenho agronômico de cultivares de soja. Pesquisa Agropecuária Brasileira, v. 47, n. 1, p. 14-21, 2012. Referencial de internet disponível em: < http://seer.sct.embrapa.br/index.php/pab/article/view/11563>. Acesso em: 17, mar, 2019;

OLIVEIRA, ARNOLD. BARBOSA de. Fenologia, desenvolvimento e produtividade de cultivares de soja em função de épocas de semeadura e densidades de plantas. 2010. 78 f. 2010. Tese de Doutorado. Dissertação (Mestrado)-Universidade Estadual Paulista de Ciências Agrárias e Veterinárias, Jaboticabal, São Paulo. Referencial de internet disponível em: <https://repositorio.unesp.br/handle/11449/96926>. Acesso em: 13, jan, 2019;

PAZZIN, DALCIONEI. Comportamento de cultivares de soja cultivadas em solo de várzea submetidas a períodos de excesso hídrico. 2012. Dissertação de Mestrado. Universidade Federal de Pelotas. Referencial de internet disponível em: $<$ http://repositorio.ufpel.edu.br:8080/handle/123456789/1530>. Acesso em: 23, jan, 2019;

PEIXOTO, C. P., \& MARTINS, M. C. Crescimento e produtividade de soja em diferentes épocas de semeadura no oeste da Bahia. Scientia Agraria, v. 11, n. 1, p. 033-042, 2010. Referencial de internet disponível em: <https://revistas.ufpr.br/agraria/article/view/15941>. Acesso em: 23, mai, 2019;

PEIXOTO, C. P., CÂMARA, G. M. D. S., MARTINS, M. C., MARCHIORI, L. F. S., GUERZONI, R. A., \& MATTIAZZI, P. Épocas de semeadura e densidade de plantas de soja: I. Componentes da produção e rendimento de grãos. Scientia agricola, 2000. Referencial de internet disponível em: <http://agris.fao.org/agrissearch/search.do?recordID=DJ2012032204>. Acesso em: 21, mai, 2019;

PINTO, F. F., BALARDIN, R., DEBORTOLI, M., \& MADALOSSO, M. Desempenho de cultivares de soja em áreas de várzeas. Revista Cultivar, ed. 175. 2013. Referencial de internet disponível em: <https://www.grupocultivar.com.br/artigos/desempenho-decultivares-de-soja-em-areas-de-varzeas>. Acesso em: 16, jan, 2019;

RODRIGUES, O., TEIXEIRA, M. C. C., COSTENARO, E. R., \& AVOZANI, A. Rendimento de grãos de soja em semeadura tardia. Embrapa Trigo-Boletim de Pesquisa e Desenvolvimento (INFOTECA-E), 2008. Referencial de internet disponível em: < https://www.infoteca.cnptia.embrapa.br/bitstream/doc/852150/1/pbp66.pdf>. Acesso em: 14, mar, 2019;

RODRIGUES, O., DIDONET, A. D., LHAMBY, J. C. B., BERTAGNOLLI, P. F., \& LUZ, J. S. D. Resposta quantitativa do florescimento da soja à temperatura e ao fotoperíodo. Pesquisa Agropecuária Brasileira, v. 36, n. 3, p. 431-437, 2001. 
Referencial de internet disponível em:

<http://www.scielo.br/pdf/\%0D/pab/v36n3/4785.pdf>. Acesso em: 03, mar, 2019;

SETIYONO, T. D., WEISS, A., SPECHT, J., BASTIDAS, A. M., CASSMAN, K. G., \& DOBERMANN, A. Understanding and modeling the effect of temperature and daylength on soybean phenology under high-yield conditions. Field crops research, v. 100, n. 23, p. 257-271, 2007. Referencial de internet disponível em:

<https://www.sciencedirect.com/science/article/pii/S0378429006001560?via\%3Dihub>. Acesso em: 05, mar, 2019;

STRECK, Edemar Valdir et al. Solos do Rio Grande do Sul. - 2 ed.- Porto Alegre: EMATER/RS-ASCAR, 2008. 222p. ISBN 978-85-98842-04-2;

TRENTIN, R., HELDWEIN, A. B., STRECK, N. A., TRENTIN, G., \& SILVA, J. C. D. Subperíodos fenológicos e ciclo da soja conforme grupos de maturidade e datas de semeadura. Embrapa Pecuária Sul-Artigo em periódico indexado (ALICE), 2013. Referencial de internet disponível em:

<https://www.alice.cnptia.embrapa.br/bitstream/doc/969444/1/48n07a02.pdf>. Acesso em: 17, mai, 2019;

VENTURA, F., MARLETTO, V., TRAINI, S., TOMEI, F., BOTARELLI, L., \& PISA, P. $R$. Validation of development models for winter cereals and maize with independent agrophenological observations in the $\mathrm{BBCH}$ scale. Italian Journal of

Agrometeorology. v. 3, p. 17-26, 2009. Referencial de internet disponível em: <https://www.agrometeorologia.it/documenti/Rivista2009_3/Ria3_2009Ventura.pdf>. Acesso em: 15, jan, 2019;

VIZZOTTO, VANDRO ROGERIO. Desempenho de mecanismos sulcadores de semeadora-adubadora sobre os atributos físicos do solo em várzea no comportamento da cultura da soja (Glycine Max L). 2014. Tese de Doutorado. Universidade Federal de Santa Maria. Referencial de internet disponível em: <http://repositorio.ufsm.br/handle/1/3620>. Acesso em: 13, jan, 2019. 